\section{$\underset{\substack{\text { hommes } \\ \text { \& migrations }}}{ }$}

\section{Hommes \& migrations}

Revue française de référence sur les dynamiques

migratoires

1333 | 2021

L'enfance en exil

\title{
Barbara Petit, Le voyage d'Albina
}

Lille, La Voix du Nord éditions, 2021, 76 p., 8,90€.

\section{Marie Poinsot}

\section{(2) OpenEdition}

1 Journals

\section{Édition électronique}

URL : https://journals.openedition.org/hommesmigrations/12748

DOI : 10.4000/hommesmigrations. 12748

ISSN : 2262-3353

Éditeur

Musée national de l'histoire de l'immigration

\section{Édition imprimée}

Date de publication : 1 avril 2021

Pagination : 222

ISBN : 978-2-919040-55-1

ISSN : 1142-852X

\section{Référence électronique}

Marie Poinsot, «Barbara Petit, Le voyage d'Albina », Hommes \& migrations [En ligne], 1333 | 2021, mis en ligne le 01 avril 2021, consulté le 26 juillet 2021. URL : http://journals.openedition.org/

hommesmigrations/12748; DOI : https://doi.org/10.4000/hommesmigrations.12748 


\section{Livres}

\section{Le voyage d'Albina}

Barbara Petit, Lille, La Voix du Nord éditions, 2021, 76 p., $8,90 €$.

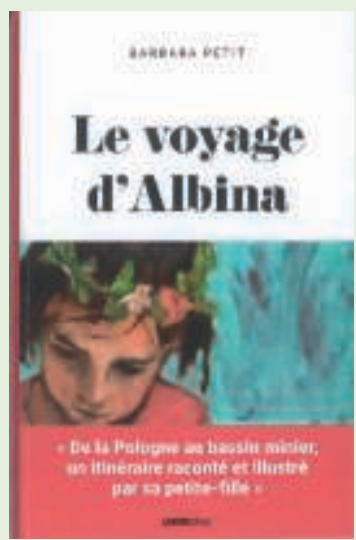

Barbara Petit est la petite fille de Albina, une jeune Polonaise qui arrive en France pour y travailler alors qu'elle est âgée de 18 ans. Ce petit ouvrage est le récit de la trajectoire migratoire d'une grand-mère disparue qui a été reconstituée par l'auteure d'après les échanges qu'elle a pu avoir avec les membres de sa famille. Albina est une femme forte et ambitieuse, dotée d'une capacité d'adaptation extraordinaire face à la dureté de la réalité migratoire, qui arrive en 1933 comme ouvrière agricole à Aire-surla-Lys avant de se marier avec Émile, un mineur de fond, en 1939, et de s'installer avec lui à Hurionville dans l'Artois. Cet hommage évoque une histoire restée invisible, celle de ces migrations féminines d'origine polonaise de l'entre-deuxguerres qui concernent des centaines de milliers de femmes souvent jeunes et célibataires et fait suite à la signature, à Varsovie le 3 septembre 1919, d'une convention franco-polonaise pour le recrutement massif de travailleurs et travailleuses. Son objectif est de répondre, avec une main-d'œuvre d'origine rurale pour la plupart, à l'effort de reconstruction des territoires et des secteurs économiques dévastés par la guerre, dont l'agriculture, la mine et la sidérurgie.

Il faut saluer cette heureuse initiative portée par le quotidien La Voix du Nord à travers son activité éditoriale et qui permet de rendre compte des histoires migratoires singulières de cette vaste région des Hauts-de-France. Le récit nous plonge dans l'histoire d'Albina, que Barbara Petit interpelle en s'adressant à elle dans le texte à la deuxième personne, comme pour raviver ce dialogue interrompu par la disparition de sa grand-mère. L'ouvrage est richement illustré par des reproductions des peintures à huile sur papier que Barbara Petit, artiste peintre installée à Paris, a réalisées pour donner une tonalité plus concrète et attachante au récit d'Albina avec des représentations des lieux et des personnages tracés avec des aplats de couleur chaude. L'ouvrage est complété par un cahier de documents, intitulé «L'album souvenirs», qui reproduit des photographies de famille, des documents administratifs, un arbre généalogique d'Albina, une note historique sur l'ampleur de la migration polonaise en France, suivie d'une chronologie et d'une cartographie régionale fort utiles pour documenter et contextualiser cette trajectoire individuelle. On ne peut qu'encourager La Voix du Nord à poursuivre cette petite collection de récits personnels venus d'ailleurs qui devrait avoir une diffusion large vers les lecteurs du quotidien et apporte des voix et des visages aux mille expériences de l'immigration d'hier.

Marie Poinsot 